\title{
Endovascular Treatment of Complex Vascular Diseases of the Internal Carotid Artery Using the Willis Covered Stent: Preliminary Experience and Technical Considerations
}

\author{
Lin Ma, Hao Feng, Shuo Yan, Ji-Chong Xu, Hua-Qiao Tan and Chun Fang* \\ Department of Interventional Radiology, Shanghai Tongji Hospital, Tongji University School of Medicine, Shanghai, China
}

OPEN ACCESS

Edited by:

Atilla Ozcan Ozdemir, Eskişehir Osmangazi University, Turkey

Reviewed by:

Ahmed Mohamed Elhfnawy, University Hospital Essen, Germany Ashish Kulhari,

JFK Medical Center, United States

${ }^{*}$ Correspondence:

Chun Fang

fang1972@vip.sina.com

Specialty section

This article was submitted to Endovascular and Interventional

Neurology,

a section of the journal

Frontiers in Neurology

Received: 23 April 2020 Accepted: 21 September 2020 Published: 29 October 2020

Citation:

Ma L, Feng H, Yan S, Xu J-C, Tan H-Q and Fang $C$ (2020) Endovascular Treatment of Complex Vascular Diseases of the Internal Carotid Artery Using the Willis Covered Stent: Preliminary Experience and Technical

Considerations.

Front. Neurol. 11:554988. doi: 10.3389/fneur.2020.554988
Purpose: The Willis covered stent (WCS) is used to treat complex vascular diseases of the internal carotid artery; however, its performance requires further investigation. This study aimed to present our single-center clinical results and experience of endovascular repair of complex vascular diseases of the internal carotid artery using the WCS.

Methods: Patients who presented with complex vascular diseases of the internal carotid artery and who were treated with the WCS from December 2013 to September 2018 were retrospectively reviewed. Procedural results, perioperative complications, incidence of endoleak, and follow-up outcomes were analyzed.

Results: Sixty-five patients were enrolled. A total of 25 large aneurysms, 10 pseudoaneurysms, 14 blood blister-like aneurysms, 11 carotid-cavernous fistulas, and 5 surgical injuries were assessed. WCS placement was successful in all patients. Immediate angiography showed that complete repair of the target artery was achieved in 56 patients (86.2\%). Endoleak was observed in nine patients, including seven type I endoleaks and two type II endoleaks. Occlusion of a side-branch vessel occurred in four patients. Acute in-stent thrombosis occurred in one patient. No ischemic or hemorrhagic events or other complications developed during the perioperative and follow-up periods. Angiographic follow-up (mean duration, $12 \pm 3.29$ months) was performed in 60 patients and showed complete target artery repair in 58 patients, and asymptomatic mild to moderate in-stent stenosis was observed in four patients. Slight endoleak persisted in two patients without enlargement or rupture of the residual lumen.

Conclusion: WCS implantation is safe, feasible, and efficacious for endovascular repair in patients with complex vascular diseases of the internal carotid artery, showing excellent short-term target artery patency and clinical outcomes.

Keywords: endovascular treatment, covered stent, internal carotid artery, aneurysm, endoleak 


\section{INTRODUCTION}

Complex vascular diseases of the internal carotid artery (ICA) are associated with a poor response and high complication rates when treated with conventional endovascular or surgical treatments. This is thought to be due to the affected anatomical structures and the morphological and histological features of these diseases. Such diseases include large aneurysms, blood blister-like aneurysms (BBAs), and carotid-cavernous fistulas (CCFs).

At present, commonly used treatments for vascular diseases of the ICA include endovascular treatment and surgery. Endovascular treatment methods include coil embolization, stent-assisted coiling, detachable balloon embolization, and flow diverter stenting (FDS) (1-4). However, high rates of incomplete occlusion and recanalization have been reported in the treatment of large aneurysms. High rates of treatment-related complications have also been observed in the treatment of BBAs, and high rates of pseudoaneurysm formation and incomplete occlusion have been observed in the treatment of CCFs (3-5). The application of frequently used surgical strategies, including vessel ligation, clipping, wrapping, trapping, and extracranialintracranial bypass, is limited by bony obstacles, adjacent vital anatomical structures of ICA, severe intraoperative bleeding, and postoperative regrowth rates (6-11).

Because of the drawbacks of routine treatments for complex vascular diseases of the ICA, innovative techniques and products are required. Recently, the Willis covered stent (WCS; MicroPort, Shanghai, China), which was designed for the intracranial vasculature, has become a promising option for the treatment of complex vascular diseases of the ICA. The WCS consists of a bare metal stent, an expandable polytetrafluoroethylene membrane covering the outside of the stent, and a rapid exchange balloon system. The specific parameters of the device and placement method have been described previously (12). The potential mechanisms of the WCS include immediate lesion exclusion from the circulation and vessel wall reconstruction.

Since its launch in China, the WCS has been widely used to treat various complicated intracranial ICA diseases and has been gradually introduced to treat extracranial ICA and vertebral artery diseases, including large aneurysms, BBAs, pseudoaneurysms, and CCFs, with promising feasibility and efficacy (13-17). Despite these encouraging results, there are insufficient data on the safety, feasibility, and efficacy of endovascular treatment of complex vascular diseases of the ICA using the WCS. In this study, we report our clinical results and experience using a retrospective analysis of 65 patients with complex vascular diseases of the ICA treated by WCS placement. To our knowledge, this study is the largest series reported on the clinical and angiographic outcomes of WCS placement for the treatment of complex vascular diseases of the ICA.

\section{MATERIALS AND METHODS}

\section{Participants}

Between December 2013 and September 2018, patients who presented with complex vascular diseases of the ICA and who were treated with WCS implantation at our institution were enrolled. The inclusion criteria were as follows: (1) the presence of a large aneurysm $(>10 \mathrm{~mm})$, traumatic or radiation-induced pseudoaneurysm, BBA, CCF, and surgical injury, located in the ICA, which was likely to be difficult to treat or presented an high risk if it was treated by conventional coil procedures or surgical treatments; (2) the modified Rankin Scale (mRS) score $\leq$ or Hunt-Hess grade $\leq$ III; (3) the patient or family member willing to sign informed consent before undergoing endovascular procedures and clinical data collection. Exclusion criteria were as follows: (1) a distance of $<2 \mathrm{~mm}$ between the aneurysm orifice and the anterior choroidal artery, fetal-type posterior communicating artery; or (2) an extremely tortuous parent artery that prohibited navigation and placement of the WCS delivery system; or (3) known allergy or contraindication to aspirin and clopidogrel, aspirin, and clopidogrel resistance or intolerance of general anesthesia; or (4) the prognosis predicted to be very poor.

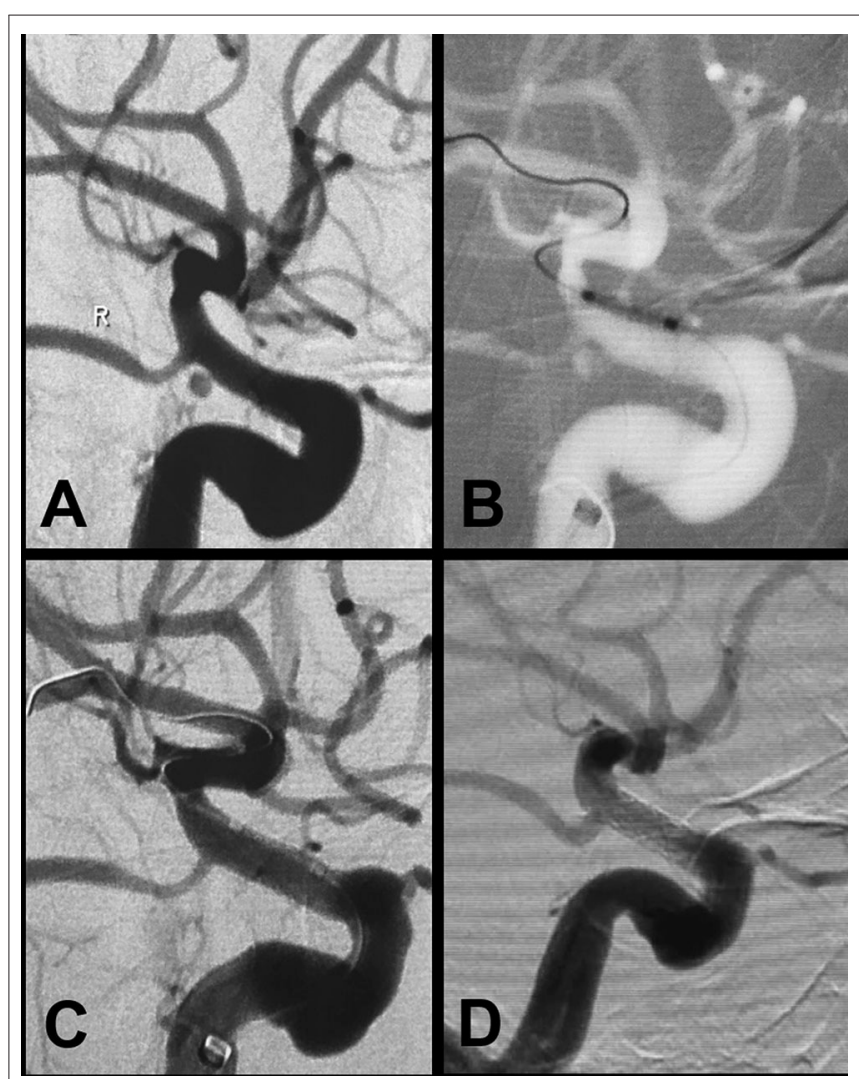

FIGURE 1 | A blood blister-like aneurysm at the ophthalmic segment of the ICA treated with the Willis covered stent. (A) Preprocedural digital subtraction angiography reveals a blood blister-like aneurysm $(2.5 \times 1.6 \mathrm{~mm})$ in the posterior wall of the ophthalmic segment of the ICA. (B) The Willis covered stent $(3.5 \times 7 \mathrm{~mm})$ was precisely delivered to the location of the aneurysm under roadmap-mask guidance. (C) Cerebral angiography immediately after stent placement demonstrates complete occlusion of the aneurysm with parent artery patency. (D) Twelve-month follow-up digital subtraction angiography shows complete obliteration of the aneurysm with no parent artery stenosis. 
Clinical data, technical results, and follow-up outcomes were analyzed. Some cases including some large aneurysms and BBAs have been reported in our previous studies $(14,18)$. This study was approved by our institutional review board committee. The ICA classification system used in this study was in accordance with the description outlined by Bouthillier et al. in 1996 (19).

\section{Endovascular Treatment Procedures}

All procedures were performed under general anesthesia. A 6-Fr long sheath (Cook, Bloomington, USA) was initially positioned in the cervical segment of the ICA. A 6-Fr Neuron (Penumbra, Alameda, California, USA) or Navien (Ev3/Covidien, California, USA) intermediate support catheter was advanced approximate to the target lesion. A $300-$ or 205-cm-long and 0.014inch-diameter micro-guidewire (Transcend, Boston Scientific, California, USA) was navigated into the distal segment of the parent artery. The WCS is available in various diameters (range, $3.5-4.5 \mathrm{~mm}$ ) and lengths (range, $7-16 \mathrm{~mm}$ ). The selected stent should be at most $0.5 \mathrm{~mm}$ wider in diameter than the target artery and at least $4 \mathrm{~mm}$ longer than the lesion neck. Under guidance of the roadmap, the stent was advanced over the micro-guidewire to bridge the lesion orifice. Multiple control angiograms were obtained to confirm the position of the stent and avoid covering the important side branch. Then, the stent was deployed using 5- to 6-atm pressure. Angiography was performed immediately after balloon deflation to confirm correct stent placement and satisfactory lesion occlusion (Figure 1).

For large aneurysms $(>10 \mathrm{~mm})$ or lesions located in curved segments or closely related to the perforating vessel, before stent deployment, several coils were placed in the cavity through another microcatheter to decrease the incidence of endoleak (Figure 2). If the lesion was located beyond the cavernous segment of the ICA, or if the parent artery was seriously tortuous, the intermediate support catheter was pushed across the segment of the lesion using a coaxial technique. Then, the stent was pushed through the support catheter to the correct position, and the support catheter was pulled back to unsheathe the covered stent, avoiding stent membrane damage during delivery, which is referred to as the intermediate-catheter "Trojan horse" technique.

\section{Antithrombotic Treatment}

Before the procedure, patients with unruptured aneurysms or CCFs were treated with daily doses of $100 \mathrm{mg}$ of aspirin and $75 \mathrm{mg}$ of clopidogrel for at least for 3 days, and

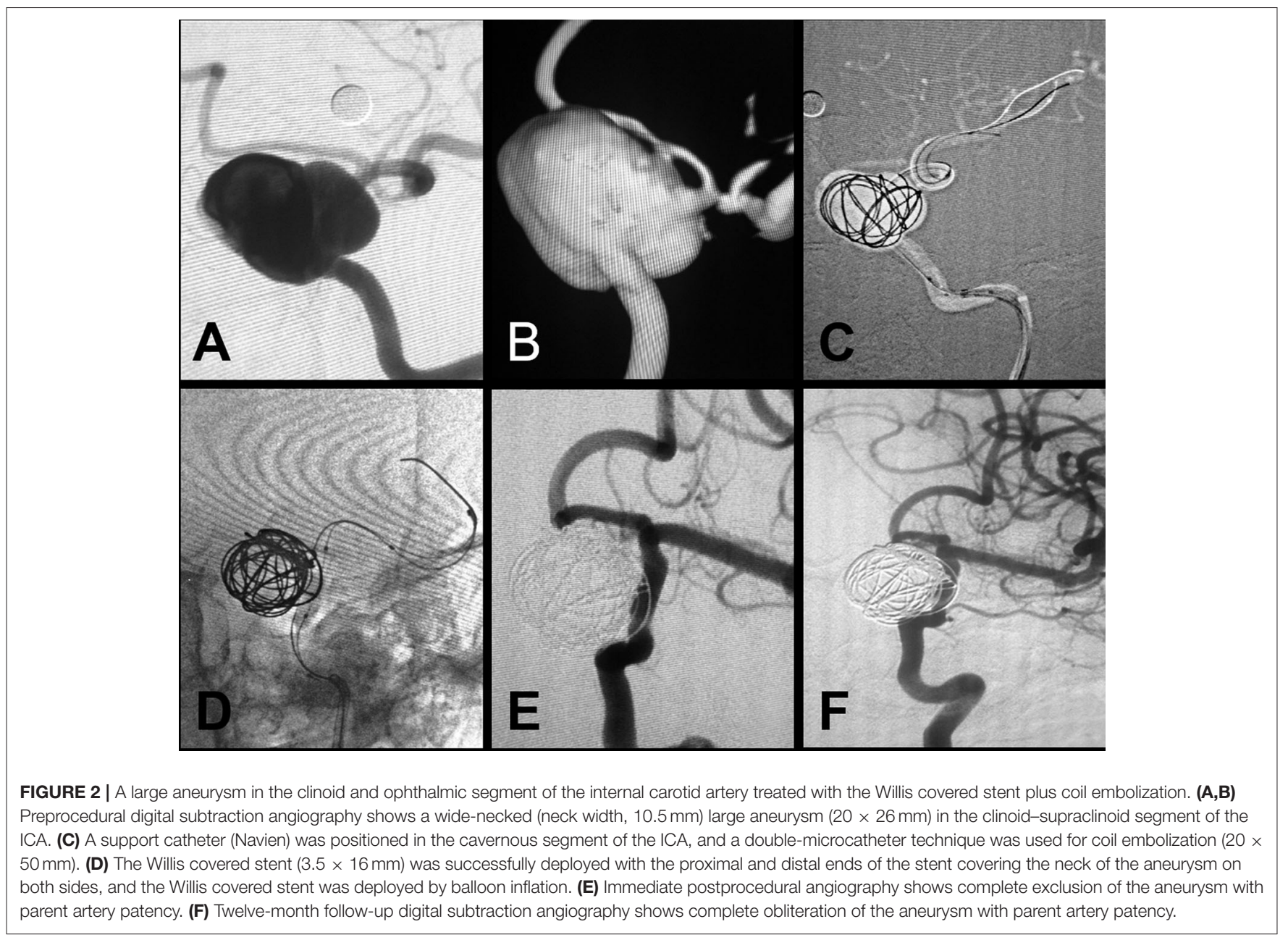


TABLE 1 | Clinical variables of the 65 patients with complex vascular diseases of the ICA treated by endovascular repair with the Willis covered stent.

\begin{tabular}{|c|c|}
\hline Variables & Values \\
\hline \multicolumn{2}{|l|}{ Sex } \\
\hline Male & 30 \\
\hline Female & 35 \\
\hline Median age (years) & $65(19-75)$ \\
\hline \multicolumn{2}{|l|}{ Location in the ICA segment } \\
\hline Supraclinoid & 20 \\
\hline Clinoid & 10 \\
\hline Cavernous & 20 \\
\hline Lacerum & 15 \\
\hline \multicolumn{2}{|l|}{ Disease category } \\
\hline Large aneurysms (>10 mm) & 25 \\
\hline Pseudoaneurysms & 10 \\
\hline Traumatic & 6 \\
\hline Radiation-induced & 4 \\
\hline Blood blister-like aneurysms & 14 \\
\hline CCF & 11 \\
\hline Traumatic & 9 \\
\hline Spontaneous & 2 \\
\hline Surgical injuries & 5 \\
\hline \multicolumn{2}{|l|}{ Clinical manifestation } \\
\hline $\mathrm{SAH}$ & 22 \\
\hline \multicolumn{2}{|l|}{$\mathrm{H} \& \mathrm{H}$ grade } \\
\hline 1 & 7 \\
\hline$\|$ & 8 \\
\hline III & 7 \\
\hline Epistaxis & 11 \\
\hline Traumatic & 4 \\
\hline Nasopharyngeal carcinoma radiotherapy & 4 \\
\hline latrogenic & 3 \\
\hline Headache & 26 \\
\hline Visual defect/diplopia & 16 \\
\hline Tinnitus & 8 \\
\hline Pituitary dysfunction & 3 \\
\hline Exophthalmos/conjunctival congestion & 12 \\
\hline \multicolumn{2}{|l|}{ Treatment strategy } \\
\hline Single covered stent & 33 \\
\hline Double covered stent & 2 \\
\hline Single covered stent plus coils & 25 \\
\hline Double covered stent plus coils & 4 \\
\hline \multicolumn{2}{|l|}{ Outcome } \\
\hline Complete occlusion & $56(86.2 \%)$ \\
\hline Endoleak & $9(13.8 \%)$ \\
\hline \multicolumn{2}{|l|}{ Endoleak type } \\
\hline Type I & 7 \\
\hline Type ॥ & 2 \\
\hline \multicolumn{2}{|l|}{ Endoleak causes } \\
\hline Poor stent adherence & 3 \\
\hline Insufficient overlap & 2 \\
\hline Backflow from the branch vessel & 2 \\
\hline Adverse events & \\
\hline
\end{tabular}

(Continued)
TABLE 1 | Continued

\begin{tabular}{lc}
\hline Variables & Values \\
\hline Acute stent thrombosis & 1 \\
Occlusion of side branch vessel & 4 \\
Ophthalmic artery & 2 \\
Anterior choroidal artery & 1 \\
Posterior communicating artery & 1 \\
Follow-up & \\
Mean time (months) & $12 \pm 3.29$ \\
Angiographic follow-up & 60 \\
Complete occlusion & $58(96.7 \%)$ \\
Endoleak & $2(3.3 \%)$ \\
In-stent stenosis & 4 \\
Clinical follow-up & 65 \\
mRS & \\
$0-1$ & 55 \\
2 & 10
\end{tabular}

ICA, internal carotid artery; SAH, subarachnoid hemorrhage; H\&H, Hunt \& Hess; CCF, carotid-cavernous sinus fistula; mRS, modified Rankin Scale.

then thrombelastography was performed to confirm drug effectiveness. For urgent conditions, such as subarachnoid hemorrhage (SAH) or epistaxis caused by ruptured aneurysms, loading doses of $300 \mathrm{mg}$ of aspirin and $300 \mathrm{mg}$ of clopidogrel were administrated through a nasogastric tube before the procedure. All patients received systemic intravenous heparin during the procedure to maintain an activated clotting time of between 250 and $300 \mathrm{~s}$. After WCS placement, tirofiban was instantly administered through an intermediate catheter to avoid acute thrombosis. After the procedure, tirofiban was administered for $48 \mathrm{~h}$ (intravenous infusion at a concentration of $0.15 \mu \mathrm{g} / \mathrm{kg}$ per minute) to avoid in-stent thrombosis in patients whose intracranial ruptured lesions were completely excluded.

Thereafter, all patients were administered a dual antiplatelet regimen for 6-12 months according to the degree of stent endothelialization, and then aspirin or clopidogrel was administered alone for at least 2 years.

\section{Imaging and Clinical Follow-Up}

Imaging follow-up was performed at 3 and 6-12 months after the procedure then annually thereafter. Clinical follow-up was performed to determine neurological deficits and any changes from baseline neurological status that were related to the devices or the procedure. This was assessed at every admission for follow-up angiography or at the outpatient clinic. The mRS score was used to evaluate the clinical state of patients. During follow-up, patients with any deterioration in neurological status were required to come back to the hospital and undergo brain computed tomography or magnetic resonance imaging if necessary. The status of the lesion was assessed by angiography to exclude the possibility of residual endoleak, aneurysmal regrowth, and in-stent stenosis. Data from the initial and final angiographic results and clinical outcomes were retrospectively 
collected and analyzed by two experienced neuroradiologists (H-Q.T. and C.F.).

\section{Statistical Analysis}

Statistical analysis was performed using the SPSS software package, version 16.0. Data are presented as mean \pm standard deviation for continuous variables, median for continuous variables with skewed distributions, or percentages for nominal variables.

\section{RESULTS}

\section{Baseline Characteristics of Patients}

A total of 65 patients (30 male and 35 female patients) were enrolled with an age range of 19 to 75 years (median, 65 years). A total of 25 large aneurysms ( $>10 \mathrm{~mm}$ ), 10 pseudoaneurysms, $14 \mathrm{BBAs}, 11 \mathrm{CCFs}$, and 5 surgical injuries were assessed. Of the 10 pseudoaneurysms, six were traumatic and four were radiation-induced. Among all enrolled patients, 22 had SAH caused by spontaneous aneurysmal rupture in 19 cases and pituitary surgery-related hemorrhage in 3 cases, including HuntHess grade I in 7 cases, grade II in 8 cases, and grade III in 7 cases. Twenty-six patients experienced headache, and 11 patients had epistaxis caused by nasopharyngeal carcinoma radiotherapy in 4 cases, traumatic injury in 4 cases, and paranasal sinus surgery-related hemorrhage in 3 cases. Sixteen patients had visual defects and/or diplopia, 8 had tinnitus, 3 had pituitary endocrine abnormalities, and 12 had exophthalmos/conjunctival congestion. Fifteen vascular diseases were located in the Bouthillier lacerum segment, 20 were located in the cavernous segment, 10 were located in the clinoid segment, and 20 were located in the supraclinoid (ophthalmic plus communicating) segment. The demographics and clinical data of patients are summarized in Table 1.

\section{Primary Procedural Results}

Primary procedural results of all patients are summarized in Tables 1, 2. Deployment of the WCS was technically successful in all patients. Among the 65 patients, 33 patients underwent single-stent implantation, 2 patients underwent double-stent implantation, 26 patients underwent single-stent plus coil embolization, and 4 patients underwent double-stent plus coil embolization. Total isolation of complex vascular diseases of the ICA was achieved immediately in 56 patients (86.2\%), and endoleak was observed in 9 patients (type I in 7 patients and type II in 2 patients), including obvious endoleak in 6 patients and slight endoleak in 3 patients (intraluminal retention of contrast media), as summarized in Table 3. Five patients with obvious type I endoleak underwent repeat balloon dilation first, and then 4 patients with sustained endoleak underwent implantation of a second WCS. For two patients with type II endoleak, one with slight endoleak underwent follow-up observation, and the other underwent branch artery embolization (Figure 3). All patients with slight endoleak underwent follow-up observation. Side-branch vessel occlusion occurred in four patients, including two cases of ophthalmic artery occlusion, one case of anterior choroidal artery occlusion, and case of one posterior communicating artery occlusion. Fortunately, no patients showed any clinical symptoms. Acute in-stent thrombosis occurred in one patient; thus, intra-arterial tirofiban was administered, which dissolved the thrombus immediately. No other complications, such as aneurysmal rupture, vessel dissection, or stent displacement, occurred during the procedure.

\section{Angiographic and Clinical Follow-Up Results}

Follow-up results are presented in Tables 1, 2. The mean follow-up period was $12 \pm 3.29$ months (range, 6-24 months). Follow-up angiography was performed in 60 patients (92.3\%), and complete target artery repair was achieved in 58 patients (96.7\%). Three patients achieved elimination of slight spontaneous endoleak, and slight endoleak without enlargement or rupture of residual lumen persisted in two patients. Only four patients showed asymptomatic mild to moderate in-stent stenosis. Telephone follow-up assessments were conducted for the remaining patients. During the follow-up period, no ischemic/hemorrhagic events or deaths occurred. Moreover, patients with side-branch vessel occlusion showed no related clinical symptoms. The mRS score at follow-up was $0-1$ in 55 patients and 2 in 10 patients.

\section{DISCUSSION}

In this study, we described our clinical results and experience of endovascular repair of complex vascular diseases of the ICA using the WCS. We also showed that WCS implantation is relatively feasible and efficacious in selected cases; therefore, this approach may be a suitable treatment option for patients with complex vascular diseases of the ICA. The technical success rate, procedural results, and angiographic and clinical follow-up outcomes were consistent with those reported previously $(18,20)$.

Based on our experience, the advantages of the WCS can be summarized as follows: immediate lesion exclusion from the circulation and vessel wall reconstruction; simple, time-saving, and minimally invasive; low risk of procedure-related rupture or rebleeding because of no/few procedural manipulations in the aneurysmal lumen; and no mass effects or aneurysm shrinkage because of no/minimal application of embolization materials. Despite the advantages mentioned above, the clinical application of the WCS has some limitations, such as the incidence of endoleak, poor target arrival rate when passing the tortuous intracranial vasculature, and side-branch occlusion, which require further discussion.

\section{Endoleak Management}

Endoleak is a common phenomenon during endovascular treatment with covered stents, which implies failure to exclude the disease and carries a high risk of lesion recurrence. Thus, endoleak has become a significant issue after using the covered stent. Generally, endoleak is caused by incomplete occlusion of the disease orifice after covered stent placement, which can be classified into types I-IV according to the source of blood flow $(21,22)$. Type I endoleak, resulting from blood flow that 
TABLE 2 | Summary of treatment, outcome, and follow-up data for 65 patients with complex vascular diseases of the ICA.

\begin{tabular}{|c|c|c|c|c|c|c|c|c|c|c|c|}
\hline \multirow{2}{*}{$\begin{array}{l}\text { Disease } \\
\text { category }\end{array}$} & \multirow[t]{2}{*}{ Cases } & \multicolumn{4}{|c|}{ Treatment strategy } & \multicolumn{2}{|c|}{ Immediate angiography } & \multirow{2}{*}{$\begin{array}{l}\text { Follow-up } \\
\text { (12 } \pm 3.29 \\
\text { months) }\end{array}$} & \multicolumn{3}{|c|}{ Follow-up angiography } \\
\hline & & $\begin{array}{l}\text { Single } \\
\text { wcs }\end{array}$ & $\begin{array}{l}\text { Double } \\
\text { wCS }\end{array}$ & $\begin{array}{l}\text { Single WCS } \\
\text { plus coils }\end{array}$ & $\begin{array}{c}\text { Double WCS } \\
\text { plus coils }\end{array}$ & Occlusion & Endoleak & & Occlusion & Endoleak & $\begin{array}{l}\text { In-stent } \\
\text { stenosis }\end{array}$ \\
\hline $\begin{array}{l}\text { Large } \\
\text { aneurysm }\end{array}$ & 25 & 4 & 1 & 18 & 2 & 20 & 5 & 23 & 22 & 1 & 2 \\
\hline Pseudoaneurysm & 10 & 8 & 0 & 2 & 0 & 10 & 0 & 9 & 9 & 0 & 0 \\
\hline $\begin{array}{l}\text { Blood } \\
\text { blister-like } \\
\text { aneurysm }\end{array}$ & 14 & 14 & 0 & 0 & 0 & 11 & 3 & 13 & 13 & 0 & 2 \\
\hline $\begin{array}{l}\text { Carotid- } \\
\text { cavernous } \\
\text { fistula }\end{array}$ & 11 & 4 & 1 & 6 & 0 & 10 & 1 & 10 & 9 & 1 & 0 \\
\hline Surgical injury & 5 & 3 & 0 & 0 & 2 & 5 & 0 & 5 & 5 & 0 & 0 \\
\hline Total & 65 & 33 & 2 & 26 & 4 & 56 (86.2\%) & $9(13.8 \%)$ & 60 (92.3\%) & 58 (96.7\%) & $2(3.3 \%)$ & $4(6.7 \%)$ \\
\hline
\end{tabular}

TABLE 3 | Endovascular treatment and angiographic follow-up results of 9 patients with endoleak.

\begin{tabular}{|c|c|c|c|c|c|c|c|c|c|c|}
\hline \multirow[t]{2}{*}{ Case No. } & \multirow{2}{*}{$\begin{array}{c}\text { Age } \\
\text { (years) }\end{array}$} & \multirow{2}{*}{$\begin{array}{l}\text { Disease } \\
\text { category }\end{array}$} & \multicolumn{2}{|c|}{ Disease status } & \multirow{2}{*}{$\begin{array}{c}\text { Treatment } \\
\text { strategy }\end{array}$} & \multirow{2}{*}{$\begin{array}{c}\text { Endoleak } \\
\text { type }\end{array}$} & \multirow{2}{*}{$\begin{array}{l}\text { Endoleak } \\
\text { treatment }\end{array}$} & \multirow[t]{2}{*}{ Outcome } & \multicolumn{2}{|c|}{ Follow-up } \\
\hline & & & $\begin{array}{l}\text { Size } \\
(\mathrm{mm})\end{array}$ & Location & & & & & $\begin{array}{c}\text { Time } \\
\text { (months) }\end{array}$ & $\begin{array}{l}\text { Endoleak } \\
\text { outcome }\end{array}$ \\
\hline 1 & 53 & BBA/SAH & $2.0 \times 3.0$ & Supraclinoid & WCS & Type I/D & Observation & - & 12 & None \\
\hline 2 & 39 & LAN & $10.5 \times 9.0$ & Clinoid & WCS+Coils & Type I/D & Observation & - & 18 & None \\
\hline 3 & 43 & CCF & - & Clinoid & WCS & Type I/P & $\mathrm{BD}+\mathrm{WCS}$ & Diminished & 13 & Slight \\
\hline 4 & 67 & LAN/SAH & $8.0 \times 12.0$ & Supraclinoid & WCS+Coils & Type I/P & $\mathrm{BD}+\mathrm{WCS}$ & Disappeared & 12 & None \\
\hline 5 & 22 & LAN & $16.0 \times 18.0$ & Lacerum & WCS & Type I/D & $\mathrm{BD}+\mathrm{WCS}$ & Diminished & 13 & Slight \\
\hline 6 & 68 & LAN & $8.0 \times 12.0$ & Clinoid & WCS+Coils & Type II & Observation & - & 8 & None \\
\hline 7 & 43 & BBA /SAH & $3.0 \times 2.0$ & Supraclinoid & WCS & Type I/D & $\mathrm{BD}$ & Disappeared & 12 & None \\
\hline 8 & 57 & BBA/SAH & $2.0 \times 2.0$ & Supraclinoid & WCS & Type II & Branch embolization & Disappeared & 10 & None \\
\hline 9 & 47 & LAN & $18.0 \times 20.0$ & Clinoid & WCS+Coils & Type I/D & $\mathrm{BD}+\mathrm{WCS}$ & Disappeared & 11 & None \\
\hline
\end{tabular}

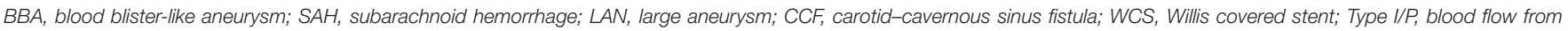
stent proximal site; Type I/D, blood flow from stent distal site; $B D$, balloon dilatation.

originates from the proximal or distal endograft attachment sites, is the most common type. Type II endoleaks represent retrograde blood flow through the ICA branch vessels into the aneurysm sac. In this study, seven type I endoleaks and two type II endoleaks were observed.

The different types of endoleak can be treated using the following strategies. First, for type I endoleak, the size of the parent artery should be carefully evaluated to select an adequately sized stent. The inflation pressure should be maintained during deployment until full apposition of the stent is achieved, and negative pressure should be maintained while gently removing the balloon. In addition, tension should be applied if the bending part is at the distal end of the lesion/tension should be reduced if the bending part is at the proximal end of the lesion during release. Also, if endoleak originates from the proximal or distal endograft attachment site, and no contrast agent is retained in the lumen during the later stages, the corresponding endograft attachment site should be dilated with the balloon, or another stent should be implanted. Finally, if retrograde flow endoleak occurs at the distal end of the stent, and contrast agent is retained in the lumen during the later stages, or slow and slight filling of the lumen is observed, follow-up observations should be considered. In this study, three patients had slight endoleak that spontaneously eliminated during follow-up.

Second, for type II endoleak, a microcatheter should be delivered to the branch artery for coil embolization. Based on previous experience of endovascular treatment of thoracic and abdominal aortic aneurysms with covered stents, type II endoleak should be treated immediately to prevent the risk of aneurysmal rupture $(23,24)$. However, we think that if endoleak blood flow is minimal, follow-up observations should be considered. In this study, one patient underwent embolization of the branch artery, and another patient underwent follow-up observation; endoleak eventually disappeared in both patients.

Third, for type III or IV endoleaks, the catheter "Trojan horse" technique should be immediately applied if the lesion is located beyond the cavernous segment, or if the parent artery is seriously tortuous, which could avoid fabric tears, graft disconnection, 


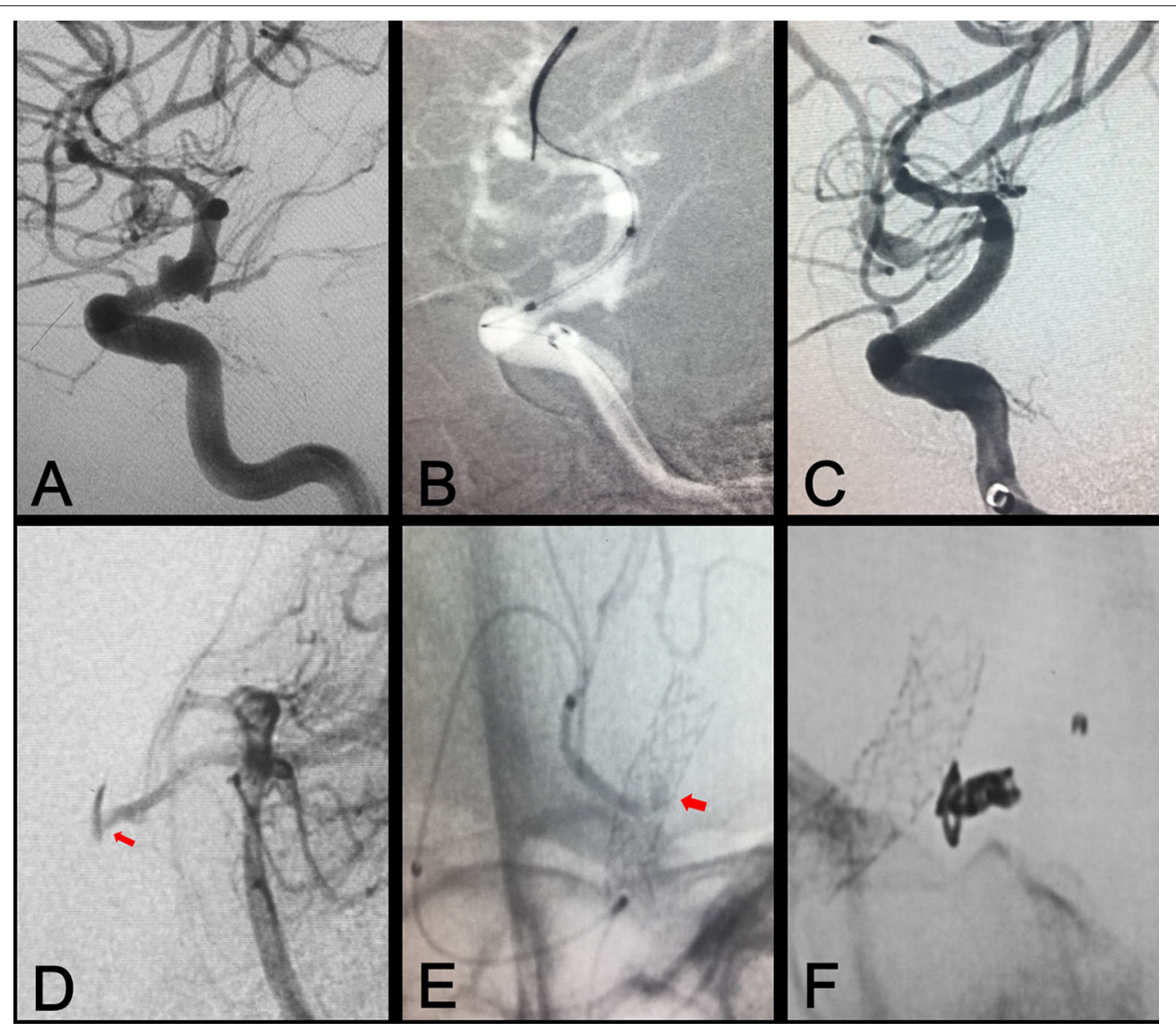

FIGURE 3 | Branch artery embolization for type II endoleak. (A) Preprocedural digital subtraction angiography shows a blood blister-like aneurysm in the ophthalmic segment of the ICA. (B) A Willis covered stent was positioned at the location of the aneurysm. (C) Immediate postprocedural angiography shows complete exclusion of the aneurysm. (D,E) Vertebral arteriography shows contrast agent on the outside of the stent, representing type II endoleak resulting from backflow from the posterior communicating artery (arrows). (F) Embolization of the posterior communicating artery with coil embolization.

or disintegration of the fabric during delivery. Once type III or IV endoleaks appear, immediate implantation of a second covered stent is recommended to prevent the risk of aneurysmal rupture (25).

Based on the above experience, the incidence and outcome of endoleak in the present study were significantly lower compared with previous studies (incidence, 13.8 vs. $30.8 \%$, respectively, outcome, 3.3 vs. $12.8 \%$, respectively) (26).

\section{Side-Branch Occlusion}

Side-branch vessel occlusion is the main disadvantage of WCS treatment as it limits the application of this procedure to certain anatomical locations of the ICA, such as the clinoid-supraclinoid segment. This is the position at which the ophthalmic artery, the posterior communicating artery, and the anterior choroidal artery originate. In our study, side-branch vessel occlusion occurred in four patients, including two cases of ophthalmic artery occlusion, one case of anterior choroidal artery occlusion, and one case of posterior communicating artery occlusion. Before the procedure, the locations of side-branch arteries and aneurysms should be carefully identified from multiple angles. If perforating arteries will inevitably be covered by the stent, the collateral circulation should be evaluated. In this study, before the procedure, the existence of a collateral circulation was verified in patients with high-risk closure of side branches. Therefore, none of the four patients in our study showed acute or delayed clinical symptoms, such as visual impairment, limb weakness, or diplopia after side-branch vessel occlusion.

Although coverage of the side-branch vessel did not cause serious neurological deficiencies in this study, closure of side branches should be avoided as much as possible. Zhu et al. reported acute right-sided visual impairment caused by closure of the right ophthalmic artery with the WCS, which might have been due to insufficient compensation of lateral branches from the external carotid artery (27). Studies have reported that the posterior communicating artery can be considered covered if the vessel is not of the fetal type (28). The anterior choroidal artery is an important side-branch of the ICA, and its occlusion can cause limb palsy, aphemia, and loss of consciousness; hence, coverage of the anterior choroidal artery should be avoided (29).

\section{In-Stent Stenosis}

In-stent stenosis is another concern of WCS placement. One report suggested that the in-stent stenosis rate of covered 
stents in the coronary circulation is $\sim 30 \%$ (30). However, in our series, four patients $(6.15 \%)$ who underwent angiographic follow-up presented with asymptomatic mild to moderate instent stenosis, similar to that reported by Tan et al. (31). We speculated that the relatively low incidence of in-stent stenosis could be ascribed to fewer risk factors for atherosclerosis in patients with dissecting/traumatic aneurysm and CCF. Moreover, a stringent dual antiplatelet therapy regimen after the procedure was another vital factor that reduced the incidence of in-stent stenosis after WCS implantation. It has been demonstrated that dual antiplatelet therapy could inhibit in-stent neointimal hyperplasia by inhibiting platelet aggregation and activation, as well as smooth muscle hyperplasia (32).

\section{LIMITATIONS}

This study has some limitations that should be highlighted. First, long-term patient follow-up was not conducted; hence, the long-term patency of the WCS and in-stent stenosis rate remain unclear. Second, our study adopted a retrospective design and lacked a comparative control group of patients undergoing other treatments, such as stent-assisted coil embolization or FDS. Third, the number of patients enrolled was relatively small, so a larger sample size is required to confirm the outcomes.

\section{CONCLUSION}

Our study revealed that the treatment of patients with complex vascular diseases of the ICA using WCS implantation is relatively safe, feasible, and efficacious. The WCS showed excellent shortterm target artery patency and satisfactory clinical outcomes. WCS implantation could be a feasible method for complex vascular diseases of the ICA treatment by lesion isolation and vessel wall reconstruction. Endoleak is the major issue after initial covered stent placement, which can be eliminated or dramatically diminished by repeat balloon dilation and/or placement of an

\section{REFERENCES}

1. Ihn YK, Kim SH, Sung JH, Kim TG. The efficacy of endovascular treatment of ruptured blood blister-like aneurysms using stent-assisted coil embolization. Interv Neuroradiol. (2012) 18:432-41. doi: 10.1177/1591019912018 00409

2. Fang YB, Li Q, Yang PF, Huang QH, Zhao WY, Xu Y, et al. Treatment of blood blister-like aneurysms of the internal carotid artery with stent-assisted coil embolization. Clin Neurol Neurosurg. (2013) 115:9205. doi: 10.1016/j.clineuro.2012.09.022

3. van Rooij WJ, Sluzewski M, Metz NH, Nijssen PC, Wijnalda D, Rinkel GJ, et al. Carotid balloon occlusion for large and giant aneurysms: evaluation of a new test occlusion protocol. Neurosurgery. (2000) 47:11621. doi: 10.1227/00006123-200007000-00025

4. Luo CB, Teng MM, Yen DH, Chang FC, Lirng JF, Chang CY. Endovascular embolization of recurrent traumatic carotid-cavernous fistulas managed previously with detachable balloons. J Trauma. (2004) 56:1214-20. doi: 10.1097/01.TA.0000131213.93205.57

5. Li MH, Chen SW, Li YD, Chen YC, Cheng YS, Hu DJ, et al. Prevalence of unruptured cerebral aneurysms in Chinese adults aged 35 additional covered stent. Nevertheless, the clinical outcomes need to be further confirmed by studies with a longer follow-up period and controlled studies with larger sample sizes.

\section{DATA AVAILABILITY STATEMENT}

The raw data supporting the conclusions of this article will be made available by the authors, without undue reservation.

\section{ETHICS STATEMENT}

Written informed consent was obtained from the individual(s) for the publication of any potentially identifiable images or data included in this article.

\section{AUTHOR CONTRIBUTIONS}

All authors contributed to the study conception and design, commented on previous versions of the manuscript, read, and approved the final manuscript. Material preparation, data collection, and analysis were performed by LM, HF, SY, and J-CX. The first draft of the manuscript was written by LM, H-QT, and CF.

\section{FUNDING}

This work was supported by the Project from Shanghai Natural Science Fund Project (Grant No. 19ZR1449000), Three-year plan program by Shanghai Shen Kang Hospital Development Center (Grant No. 16CR3043A), Priority of Shanghai Key Discipline of Medicine (Grant No. 2017ZZ02020), Training Program of Shanghai Tongji Hospital [Grant No. GJPY1812 and ITJ (ZD) 1907], Shanghai Rising Stars of Medical Talent Youth Development Program [Grant no. (2019) 72], and Program of Outstanding Young Scientists of Tongji Hospital of Tongji University (Grant No. HBRC1808). to 75 years: a cross-sectional study. Ann Intern Med. (2013) 159:51421. doi: 10.7326/0003-4819-159-8-201310150-00004

6. Gomez F, Escobar W, Gomez AM, Gomez JF, Anaya CA. Treatment of carotid cavernous fistulas using covered stents: midterm results in seven patients. AJNR Am J Neuroradiol. (2007) 28:1762-8. doi: 10.3174/ajnr.A0636

7. Kazumata K, Nakayama N, Nakamura T, Kamiyama H, Terasaka S, Houkin K. Changing treatment strategy from clipping to radial artery graft bypass and parent artery sacrifice in patients with ruptured blister-like internal carotid artery aneurysms. Neurosurgery. (2014) 10(Suppl. 1):6672. doi: 10.1227/NEU.0000000000000076

8. Kubo Y, Koji T, Yoshida K, Saito H, Ogawa A, Ogasawara K. High-flow bypass and wrap-clipping for ruptured blood blister-like aneurysm of the internal carotid artery using intraoperative monitoring of cerebral hemodynamics. Vasc Health Risk Manag. (2015) 11:297-302. doi: 10.2147/VHRM. S73779

9. Lawton MT, Spetzler RF. Surgical management of giant intracranial aneurysms: experience with 171 patients. Clin Neurosurg. (1995) 42:245-66.

10. Raaymakers TW, Rinkel GJ, Limburg M, Algra A. Mortality and morbidity of surgery for unruptured intracranial aneurysms: a meta-analysis. Stroke. (1998) 29:1531-8. doi: 10.1161/01.str.29.8.1531 
11. Parkinson RJ, Eddleman CS, Batjer HH, Bendok BR. Giant intracranial aneurysms: endovascular challenges. Neurosurgery. (2008) 62:1336-45. doi: 10.1227/01.NEU.0000333798.67209.1F

12. Li MH, Li YD, Gao BL, Fang C, Luo QY, Cheng YS, et al. A new covered stent designed for intracranial vasculature: application in the management of pseudoaneurysms of the cranial internal carotid artery. AJNR Am J Neuroradiol. (2007) 28:1579-85. doi: 10.3174/ajnr.A0668

13. Tan HQ, Li MH, Li YD, Fang C, Wang JB, Wang W, et al. Endovascular reconstruction with the Willis covered stent for the treatment of large or giant intracranial aneurysms. Cerebrovasc Dis. (2011) 31:154-62. doi: 10.1159/000321735

14. Fang C, Tan HQ, Han HJ, Feng H, Xu JC, Yan S, et al. Endovascular isolation of intracranial blood blister-like aneurysms with Willis covered stent. J Neurointerv Surg. (2017) 9:963-8. doi: 10.1136/neurintsurg-2016-012662

15. Liu LX, Lim J, Zhang CW, Lin S, Wu C, Wang T, et al. Application of the Willis covered stent in the treatment of carotid-cavernous fistula: a single-center experience. World Neurosurg. (2019) 122:e390-8. doi: 10.1016/j.wneu.2018.10.060

16. Li MH, Gao BL, Wang YL, Fang C, Li YD. Management of pseudoaneurysms in the intracranial segment of the internal carotid artery with covered stents specially designed for use in the intracranial vasculature: technical notes. Neuroradiology. (2006) 48:841-6. doi: 10.1007/s00234-006-0127-7

17. Xiang S, Li G, He C, Ren J, Zhang H. Reconstructive endovascular treatment of the V4 segment of a vertebral artery dissecting aneurysm with the Willis covered stent: a retrospective study. Interv Neuroradiol. (2019) 25:54855. doi: 10.1177/1591019918824413

18. Ma L, Xu JC, Yan S, Feng H, Han HJ, Tan HQ, et al. A single-center experience in the endovascular treatment of carotid siphon aneurysms using the Willis covered stent: a retrospective analysis. J Neurointerv Surg. (2018) 10:1197-202. doi: 10.1136/neurintsurg-2017-013695

19. Bouthillier A, van Loveren HR, Keller JT. Segments of the internal carotid artery: a new classification. Neurosurgery. (1996) 38:425-32; discussion: 323. doi: 10.1227/00006123-199603000-00001

20. Liu Y, Yang HF, Xiong ZY, Zheng J, Liu CY, Zhao HY, et al. Efficacy and safety of Willis covered stent for treatment of complex vascular diseases of the internal carotid artery. Ann Vasc Surg. (2019) 61:20311. doi: 10.1016/j.avsg.2019.05.027

21. Chaer RA, DeRubertis BG, Trocciola S, Hynecek R, Lin SC, Lam $\mathrm{R}$, et al. Characterization of endoleak following endovascular repair of abdominal aortic aneurysms. Vasc Endovasc Surg. (2007) 41:97105. doi: $10.1177 / 1538574406297252$

22. White GH, Yu W, May J, Chaufour X, Stephen MS. Endoleak as a complication of endoluminal grafting of abdominal aortic aneurysms: classification, incidence, diagnosis, and management. J Endovasc Surg. (1997) 4:152-68. doi: 10.1177/152660289700400207

23. Schurink GW, Aarts NJ, van Bockel JH. Endoleak after stent-graft treatment of abdominal aortic aneurysm: a meta-analysis of clinical studies. Br J Surg. (1999) 86:581-7. doi: 10.1046/j.1365-2168.1999.01119.x

24. Steinmetz E, Rubin BG, Sanchez LA, Choi ET, Geraghty PJ, Baty J, et al. Type II endoleak after endovascular abdominal aortic aneurysm repair: a conservative approach with selective intervention is safe and cost-effective. J Vasc Surg. (2004) 39:306-13. doi: 10.1016/j.jvs.2003.10.026

25. Zeng $\mathrm{S}$, Yang $\mathrm{H}$, Yang $\mathrm{D}$, $\mathrm{Xu} \mathrm{L}, \mathrm{Xu} \mathrm{M}$, Wang $\mathrm{H}$. Case report of late type IIIb endoleak with Willis Covered Stent (WCS) and literature review. World Neurosurg. (2019) 130:160-4. doi: 10.1016/j.wneu.2019. 06.105

26. Zhu YQ, Li MH, Xie J, Tan HQ, Cheng YS, Wang JB. Treatment of carotid siphon aneurysms by use of the Willis stent graft: an angiographic and histopathological study. Eur Radiol. (2010) 20:197484. doi: 10.1007/s00330-010-1738-2

27. Zhu YQ, Li MH, Lin F, Song DL, Tan HQ, Gu BX, et al. Frequency and predictors of endoleaks and long-term patency after covered stent placement for the treatment of intracranial aneurysms: a prospective, non-randomised multicentre experience. Eur Radiol. (2013) 23:287-97. doi: 10.1007/s00330-0122581-4

28. Li MH, Zhu YQ, Fang C, Wang W, Zhang PL, Cheng YS, et al. The feasibility and efficacy of treatment with a Willis covered stent in recurrent intracranial aneurysms after coiling. AJNR Am J Neuroradiol. (2008) 29:1395400. doi: 10.3174/ajnr.A1096

29. $\mathrm{Yu} \mathrm{J}, \mathrm{Xu} \mathrm{N}$, Zhao $\mathrm{Y}, \mathrm{Yu}$ J. Clinical importance of the anterior choroidal artery: a review of the literature. Int J Med Sci. (2018) 15:36875. doi: $10.7150 /$ ijms. 22631

30. Stankovic G, Colombo A, Presbitero P, van den Branden F, Inglese $\mathrm{L}$, Cernigliaro $\mathrm{C}$, et al. Randomized evaluation of polytetrafluoroethylene-covered stent in saphenous vein grafts: the randomized evaluation of polytetrafluoroethylene COVERed stent in saphenous vein grafts (RECOVERS) trial. Circulation. (2003) 108:37-42. doi: 10.1161/01.CIR.0000079106.71097.1C

31. Tan HQ, Li MH, Zhang PL, Li YD, Wang JB, Zhu YQ, et al. Reconstructive endovascular treatment of intracranial aneurysms with the Willis covered stent: medium-term clinical and angiographic follow-up. J Neurosurg. (2011) 114:1014-20. doi: 10.3171/2010.9.JNS10373

32. Hemetsberger R, Farhan S, Strehblow C, Sperker W, Pavo I, Petrasi Z, et al. Association between the efficacy of dual antiplatelet therapy and the development of in-stent neointimal hyperplasia in porcine coronary arteries. Coron Artery Dis. (2008) 19:635-43. doi: 10.1097/MCA.0b013e32831 425 ed

Conflict of Interest: The authors declare that the research was conducted in the absence of any commercial or financial relationships that could be construed as a potential conflict of interest.

Copyright (C) 2020 Ma, Feng, Yan, Xu, Tan and Fang. This is an open-access article distributed under the terms of the Creative Commons Attribution License (CC BY). The use, distribution or reproduction in other forums is permitted, provided the original author(s) and the copyright owner(s) are credited and that the original publication in this journal is cited, in accordance with accepted academic practice. No use, distribution or reproduction is permitted which does not comply with these terms. 